\title{
Towards norms and standards for water services in rural South Africa
}

\author{
L. C. Duncker \\ CSIR, Built Environment, South Africa
}

\begin{abstract}
In South Africa, the current norms and standards for levels of water services have, over the last few decades, inadvertently focused on addressing water services in urban areas. The Minister responsible for water and sanitation initiated the development of revised norms and standards for equitable water services to all citizens, taking into account availability of water resources, financial challenges, geographical placement issues, servicing vulnerable groups and addressing the backlog, especially in rural areas. The project followed a participatory approach by focussing on workshops with key stakeholders and role players in the water sector, and work sessions with officials and implementers at national and local levels. The process culminated in revised goal and principles for appropriate levels of water services for the development of norms and standards that will be applied in the rural landscape of South Africa.

Keywords: water, water service, level of water services, norms, standards, participatory development, water ladder, water quality, equity, sustainability, affordability, effective and efficient, appropriate.
\end{abstract}

\section{Introduction}

The legislation that regulates water and sanitation services in South Africa is the Water Services Act No. 108 of 1997 and the National Water Act No. 36 of 1998. Both these acts fall under the ambit of the Minister responsible for water and sanitation, whose mandated functions in the domestic water use sector are to establish, monitor and regulate guidelines for policies, criteria for subsidies, and standards for water and sanitation service provision.

According to the Strategic Framework for Water Services (SFWS) of the Department of Water Affairs and Forestry [1], which is the executive strategy for 
the water acts, it is the responsibility of a Water Services Authority to ensure that "adequate and appropriate investments are made to ensure the progressive realisation of the right of all people in its area of jurisdiction to receive at least a basic level of water and sanitation services", i.e. a universal service obligation. Actual delivery of the water and sanitation services is thus the responsibility of local government.

A National Water Policy Review (NWPR) by the Department of Water Affairs [2] resulted in the prioritisation of access to basic water supply in the form of a yard connection to all households in the country. The Minister responsible for water initiated the development of norms and standards for equitable water services provision to households, which are aligned with the SFWS and take into account availability of water resources, financial challenges, geographical placement issues, servicing of vulnerable groups and addressing the backlog.

The focus of this paper is on the review of the current norms and standards for water provision in South Africa towards developing appropriate norms and standards for levels of services in provision of water. The norms and standards for sanitation and waste water are currently earmarked for revision.

\section{Method}

The process of developing norms and standards for levels of services in the provision of water to people consisted of a desktop revision of the existing and current norms and standards, the practices around applying these norms and standards, and determining how they fit within the international thinking, the national planning and the local implementation contexts.

This desktop revision resulted in a background document that comprised the current standards, norms and practices in the provision of water to consumers. This background document was used as a discussion point in a workshop with key stakeholders and role players in the water sector in South Africa, with the aim to act as a reference group providing guidance in the development of appropriate norms and standards for provision of water to consumers. The feedback from this group of expert is being used to propose norms and standards for appropriate levels of service in the provision of water to people in South Africa.

The proposed norms and standards for level of water services are being developed in a participative manner and are in the process of being presented and discussed at a national workshop with stakeholders and role players in the water sector, as well as at nine regional workshops with local government and implementing agencies responsible for water services. The discussions and comments from the participants in these sessions are expected to be extensive and will be incorporated in the finalisation of the norms and standards for appropriate levels of water services.

\section{Discussion}

During the process of developing the norms and standards for appropriate levels of water services, a comprehensive literature review of international and national 
practices revealed the crucial and far-reaching factors affecting norms and standards in the provision of water, especially in rural areas.

South Africa has a population of close to 55 million, of which about $38 \%$ live in the rural areas, the majority of them poor. The provision of water to these people has inadvertently been scaled according to water provision in urban areas, but experience has shown that, even if the classification of levels of services may be applicable to urban as well as rural areas, the methods and approaches used to deliver the services in rural areas in some cases radically differ from those in urban areas. The factors affecting levels of services in the provision of water are reflected below.

\subsection{Defining the indigent}

One of the most vexing challenges in provision of safe drinking water is reaching the section of the population that is unable to pay for water services, most of whom live in rural areas. The result was that a policy and a government grant was established, aimed at providing potable water to the poor, not only for survival, but to increase the chances of improving poor people's health and well-being. This policy is called the Free Basic Services Policy that ring-fences funds for basic water and sanitation services through a Local Equitable Share Grant to service providers for the provision of water for free. The grant is specific to those households that are indigent, which were defined by the SFWS and the Free Basic Water Implementation Framework, reflected in dplg [3], as households 'lacking the necessities of life, such as sufficient water, basic sanitation, refuse removal in denser settlements, environmental health, basic energy, health care, housing, food and clothing. Anyone who does not have access to these goods and services is considered indigent'.

However, the definitions of 'indigent' vary considerably between sector departments and municipalities providing free basic services, mainly in order to accommodate the variety of conditions and contexts service providers have to face. Therefore, a combination of criteria comprises the definition of an indigent household that is eligible for free basic water. These criteria are not prescriptive to municipalities; they are allowed to use their own discretion to accommodate the realities municipalities face on a daily basis. For example, municipalities may encounter households with varying conditions that qualify them as being indigent, such as properties that have more than one dwelling structure, a dwelling with more than one household, a household with HIV/AIDS, a child-headed household, and so on.

The minimum quantity of potable water to indigent households are currently set at 25 litres per capita per day, or 6,000 litres per household per month. Each service provider has the freedom to select which level of service they can afford to provide for free to indigent households within these requirements. This has resulted in a myriad of methods and approaches, all valid, to serving the indigent across the rural areas of the country. 


\subsection{Water conservation, integrated water demand management and water re-use}

The Second National Water Resources Strategy (NWRS2) of the Department of Water Affairs [4] states that: "Many parts of the country have either reached, or are fast approaching, the point at which all the financially viable freshwater resources are fully utilised and where building of new dams will not address the challenges". The focus of the NWRS2 is to not increase water supply from the source, but rather to reduce demand through loss and leak rectification, or to supplement demand with water re-use.

Increasing water supply means increased quantity of wastewater for disposal that existing wastewater disposal practices and systems might not be able to cope with. In view of the projected water shortages in future and the cost of rendering water drinkable, the recycling and re-use of greywater (water used for bathing, washing dishes or washing clothes) should be encouraged. The National Development Plan, Vision for 2030 (NDP) by the National Planning Commission [5] proposed a dedicated national programme to reduce water demand and improve water use efficiency.

The CSIR [6] stated that recycling of wastewater has the potential to reduce the demand on water significantly and could be implemented where feasible and where human health will not be compromised. Greywater could, for example, be used to flush toilets, or water the garden. However, the level of knowledge of users regarding greywater use is generally low, which results in non-acceptance of the use of any type of water that is not classed as potable.

\subsection{Governance}

Good governance implies equitability, transparency, responsibility, and upward and downward accountability. In many cases, consumer dissatisfaction with water governance is at the core of perceptions of deprivation and social water scarcity, according to Tapela [7].

South Africa has devolved responsibility for provision of water services to municipalities, which are often under-resourced, both financially and in human capacity and skills, to perform this function. Similarly at a national level, even though legislative supervision is the responsibility of the Minister of water and sanitation, water service regulations and supervision/oversight are shared by a number of national departments, often in a disjointed manner, as was discussed by Duncker and Wilkinson [8]. Although the Integrated Development Plan framework is intended to ensure effective integration and coordination between various sectors and spheres of government, a study by Tapela [7] found that, in some cases, water needs expressed and prioritised by communities were not similarly prioritised in terms of implementation funding.

When water supply is seen as a series of projects where the construction of infrastructure is the most important element, rather than the provision of a service, it is bound to be unsustainable. A service includes the initial construction phase, but is predominantly an ongoing business of supplying (at a cost) water to consumers over a long period of time. Iterative, transparent, coordinated and 
cooperative planning through local government procedures can build capacity; can attract funding from other governmental and non-governmental sources and can promote convergence and pooling of resources.

A stronger link between planning processes and budgeting is extremely important, which is a major challenge amid numerous parallel operating planning processes by local government and by line agencies and other stakeholders operating through local government. Optimal water services institutions are therefore those that possess a combination of governance attributes (legitimacy, accountability, adaptability, effectiveness, efficiency) that will enhance prospects of achieving the objectives of Integrated Water Resource Management, appropriate water services, improved livelihoods and social integration.

\subsection{Social acceptance and ownership}

Many studies in South Africa have shown that social aspirations and expectations generally drive decision-making and acceptance of levels of services by consumers/users. Demand-driven approaches that are empowering communities through well-structured and informed campaigns and encouraging involvement in the decision-making process must be incorporated in the provision of water services.

A study by Naidoo et al. [9] showed that community expectations are high and residents will only accept household water connections and water borne sanitation as a level of service, thus making it difficult for a municipality to meet the expectations of its residents in a cost effective manner. Considering individuals' needs, expectations and desires are generally striven for in determining acceptable levels of services to be provided to households in the country, however, the financial resources/expenditure in establishing the service is currently the overriding factor.

The communication of/training in effective water use, hygiene and related practices play a significant role in stimulating demand for an appropriate service, ensuring participation in the process and supporting the long-term acceptance and sustainability of a service provided to the household. Sustainable water service provision should ensure that robust, on-going water conservation awareness and promotion interventions are part of the service provided.

\subsection{Finance and funding mechanisms}

Water services in South Africa are financed through the water and sanitation components in the local equitable share (LES) grant from government, while capital spending on water assets is mainly financed through the basic services component of the municipal infrastructure grant. In many cases, infrastructure grant funding is supplemented by internal sources and external borrowing by all types of municipalities. Metros contribute substantially of their own revenues towards providing water services to complement the LES grant, while municipalities generally do not do so (possibly because metros serve a larger variety of customers, including businesses and industries, compared to smaller municipalities that largely serve a residential customer base). 
Naidoo et al. [9] mentioned that in many municipalities, surplus funds generated by revenue collections for water services provided are not invested back into the water sector. Instead, funds go into a central municipal fund, which may be allocated to other departments in the municipality. This has resulted in low cost recovery, implying more reliance on government grants for provision of services.

\subsection{Operation and maintenance of infrastructure}

Operation and maintenance is critical for ensuring the sustainable functioning and use of a water supply system. Unreliable or unsustainable water supply services may result in users reverting to old, poor quality water sources or to water storage practices that may lead to increased risks of transmission of water-borne diseases.

The SFWS of the Department of Water Affairs and Forestry [1] defines a basic water supply service as... " (amongst others) communication of good water-use, hygiene and related practices". By definition a basic service includes the facility (the infrastructure), the sustainable operation of the facility. However, operation and maintenance efforts of water facilities in the provision of services by water services providers are often under-resourced, both in terms of financial resources and the capacity and skills levels of the services providers.

\section{Results}

The results of the literature review and discussions with reference group members culminated in proposing norms and standards for appropriate levels of water services, which are executable within the current capabilities and skills of services providers, but with the opportunity to build capacity and capability in providing services as well as integrated water demand management and conservation.

\subsection{Goal of the norms and standards for levels of water services}

A typical household or community needs and uses water for different purposes even if a water delivery system is designed and managed with the aim of providing a service that meets the demand for a single water use. To be prepared for this manner of water use, the concept of multiple use services serves as a departure point in developing appropriate norms and standards.

It is therefore implicit that different levels of services can co-exist in one service area and that water is used for multiple purposes (drinking, hygiene, cooking, watering livestock, growing food, generating income), thus creating an integrated approach to delivering water services that meet people's health and livelihood needs. Levels of water services need to focus on providing water to people within their contexts: i.e. the physical, social, biological environments; the governance environment; the funding mechanisms and finances; the implementation approaches, methods and technologies; the water demand for sanitation; and waste water management.

The goal and principles of levels of services in the provision of water to households and public facilities are based on mixed level of services and multiple use of water, thus: "Wherever practical, water services and infrastructure must 
provide water for multiple use and accommodate mixed levels of service within communities, allowing consumers to elect a level of service which suits their needs, is affordable to them (within the prevailing subsidy framework), addresses inequalities, utilises appropriate and upgradable technologies, and is governed transparently, effectively and responsibly to ensure sustainability”.

\subsection{Principles supporting norms and standards}

The principles for the norms and standards for appropriate levels of services are the following:

\subsubsection{Water services are sustainable}

Sustainability of a service is achieved when consumers want and accept the level of service provided, are able to pay for it and the skills are available locally to service the system or infrastructure.

Providing effective water service delivery requires a combination of management, financial, engineering, economics and social practices and techniques within a strong framework and a resilient management plan. To ensure inclusion of all sustainability aspects into water services will require delivery of a service in a manner that balances the four pillars for sustainability, i.e. economic efficiency; social equity; environmental security; and appropriate technology, which are underpinned by institutional support. The use of technology that is appropriate to the particular situation or environment in which water services are provided is of utmost significance in the sustainability of that particular service.

Sustainable water services thus require that systems are set up to ensure that the most appropriate infrastructure is provided and is properly managed; timely repairs are made in case of breakdowns; infrastructure can be renewed and replaced at the end of its useful life; and there is capacity to extend delivery systems and improve services delivery in response to changes in demand.

\subsubsection{Water services are economical and affordable}

The economic situation of water provision is fluid: goals are changing, service levels are fluctuating, technology is evolving, and consumer demand is growing.

Users typically want water that is accessible and of sufficient quantity, but have much less demand for safe water. Some users may in fact want more than what is on offer (i.e. more water, closer to the homestead), but they are not offered the choice of a higher level of service. The poor is over-represented among the unserved because they cannot afford the tariffs charged for public water services and are most in need of public support. Burr and Fonseca [10] highlighted that in many cases, users end up with services that are either above or below what they asked for or can afford, with the resulting limited payment for services, most of the time covering basic operation and maintenance costs, but rarely the rehabilitation or replacement costs.

Economic and affordable water services mean that the service provider is able to afford the provision of the service and consumers are able and willing to pay for the service. 


\subsubsection{Water services are effective and efficient}

'Effective' means the degree to which objectives are achieved and the extent to which targeted problems are solved. Effectiveness is determined without reference to cost - it means "doing the right thing", achieving the intended purposes, i.e. policy imperatives such as universal access to a minimum level of water; and social, economic and environmental imperatives of addressing the negative effects of inadequate water demand management.

'Efficient' means the accomplishment of, or ability to accomplish, a job with a minimum expenditure of time and effort; i.e. the ability to perform or function in the best possible manner with the least waste of time and effort by having and using the requisite knowledge and skills. Efficiency is determined in relation to cost - it means "doing the thing right", thus providing water in the most cost effective manner so that the benefits of the provision of water outweigh the social, economic and environmental costs of providing the water.

Effective and efficient water services mean that services are achieving their intended purposes (providing potable water) within their social, economic and environmental contexts in a cost effective manner, thus "doing the right thing right".

\subsubsection{Water services are equitable}

Providing everyone with access to water - whether male, female, wealthy or poor - is vital to improving health, livelihoods and economic growth. According to the NWPR of the Department of Water Affairs [2], equity in the water sector has several critical elements: i.e. the provision of an adequate supply of safe water to all households to meet their domestic and productive requirements, with a minimum quantity per person per day, provided free of charge to indigent households; ensuring that the authorisation to use water for productive purposes (i.e. access to water as a means of production) is transformed to align with the demographic realities of South Africa to support black economic empowerment and the development of an inclusive economy; that the allocation and use of water supports the reduction of poverty and inequality across the country; that the water needs of poor rural communities are met and protected to support the development of sustainable livelihoods; and that the indirect benefits of water from healthy river systems are protected and maintained.

Social inclusion in water and equitable allocation of funding for water require governments and policy makers to reform institutional policies and practices to take into account any informal rights that men and women have secured, said Van der Bliek et al. [11]. The NWPR of the Department of Water Affairs [2] is very much focussed on equity and motivates for different practice in the management of water in the country in response to different social (equity) needs. This principle of prioritising equity in reallocation of 'set-aside' water, which has been returned to the public trust, supports the fundamental water principles and constitutional imperatives of equity and equitable access in the country.

Equitable water services imply that local authorities do not decide which services will be provided to a household, but rather that access is determined 
jointly, with active participation of individuals and communities (men, women, marginalised and vulnerable groups).

\subsubsection{Water services are appropriate}

Water services occur within a context, therefore water service authorities and providers, at national, local and community levels, need to be aware of the relevant policies, and consider the physical, social, economic, financial, institutional and environmental frameworks in which water services are provided.

As part of the contextual factors that need to be considered in water services, demography, physical setting, settlement typology and topography have a significant impact on the sustainability of water services provision. Research showed that as the level of services rises, more people move into and settle in the area, thus placing a bigger burden on existing infrastructure and services. This may cause the need for more money to be spent on maintenance and expansion in order to provide appropriate water services.

Appropriate water services consider contextual issues, fit the scene, are accepted, are adaptable and flexible and are functional over a long period of time.

\subsection{Proposed norms and standards for appropriate levels of services}

The proposed norms and standards for appropriate levels of water services focus on progressively serving the population and achieving universal access to safe water. Levels of service allow for climbing a 'water ladder' in reaching the next level of service. In this manner, the indigent are afforded the opportunity to lift themselves out of the poverty trap by using the water allocated to them productively to improve their health and to create opportunities for income generation.

\subsubsection{Cross-cutting norms and standards for levels of services}

All levels of water services are dependent on receiving water from a bulk service, which is categorised as a water source obtaining its water from rivers, catchment areas, dams, springs and/or boreholes. It is the responsibility of the bulk services provider to ensure that the water is treated and purified to potable water standards, contained in SANS 241 of the Department of Water Affairs and Forestry [12], before making it available to be reticulated as a service to people, taking cognisance of pressure requirements. All water use and/or supply must be metered and tariffed where applicable. The setting of tariffs for water use is aimed at promoting equitable, financially viable and environmentally sustainable tariffs. Average tariffing rates must be determined for provision of potable water for survival (basic access), services (higher than basic access), sustainability and developmental purposes. Tariffs need to cover and recover capital expenditure (creation of new works or capital expenditure), operational costs (day to day running expenses), maintenance costs (planned, reactive and major maintenance activities) and capital asset management costs (expansion, rehabilitation and replacement expenditure). 


\subsubsection{Levels of service}

The proposed levels of water services aim to meet people's survival, basic and productive need for potable water, which is a human right, in an integrated manner where it is practical, affordable, financially viable and sustainable, while making the most efficient use of water resources.

The minimum level of service allows for the provision of free basic water to people who are indigent but focus on provision of potable water for basic needs through a water ladder that allows for increasing quantities of water provision within a limit of 25 to 50 litres, and that is affordable to consumers and service providers.

The proposed middle level of service is aimed at meeting people's need for potable water through climbing a water ladder within the limit of 50 to 90 litres per capita per day, which is paid for.

The full level of service provides potable water to the consumer at a constant pressure, on demand, every day, and is paid for by the consumer. A full service is the highest level of water service.

Levels of services to public facilities are aimed at meeting people's demand for potable water when not at home. Apart from educational and health care facilities, public facilities also include places where people gather and where a water services provider is responsible for provision of water, such as cemeteries, funeral parlours and crematoria, local facilities (public amenities, community halls, taxi ranks, churches, police stations, sports facilities, etc.), and public places (parks, beaches and places of leisure). No public facility is allowed to be open to the public for use without access to potable water.

\subsubsection{Supporting levels of services}

Supporting the above three levels of water provision to rural people is an interim level of service, an emergency level of service and a focus on enabling self-supply.

An interim level of service is to meet people's domestic need for potable water within 24 hours of disruption or breakdown in existing services, while an emergency level of service is aimed at providing potable water for drinking and hygiene within 24 hours of the onset of a declared emergency or disaster situation and for as long as the situation persists. The water quality must be acceptable and safe with a tolerable level of health risk to consumers.

A self-supply level of service happens when people dig their own wells or construct water harvesting systems at household level or in small groups, thus meeting their own need for domestic water supply largely or wholly through own investment. These can be individual households, or small groups of households, or schools, or clinics. The relevant regulations and protocols for groundwater and spring protection are applicable in the case of self-supply level of services.

\subsection{Monitoring, reporting and evaluation}

The NDP of the National Planning Commission [5] states that water must be managed, monitored and protected with oversight/supervision remaining a national responsibility. The Department of Water and Sanitation (DWS), as the regulator of water services in South Africa, is obliged to monitor water services 
institutions as specified in Section 62 of the Water Services Act. Monitoring, reporting and evaluation are the systematic examination of the effectiveness and efficiency of design and implementation of policies, programmes and projects in providing water services.

Monitoring and reporting on the effectiveness, appropriateness and impact of the norms and standards for water services are crucial for sustainability. A monitoring and reporting system needs to be in place to ensure the monitoring of the application of the norms and standards and the reporting of best practices and lessons learnt for adaptation and future sustainability. Currently the incentivebased Blue Drop, Green Drop and No Drop Certification Programmes assist with assessing the performance of municipalities regarding providing clean drinking water, effective water management and efficient waste water treatment systems.

\section{Conclusion}

The specific norms and standards applicable to appropriate levels of water services are in the process of being finalised, taking in consideration the current practices, and endeavouring to simplify and streamline the efforts of national and local role players responsible for water services. These are expected to be completed by August 2015. The finalised norms and standards for appropriate levels of water services will be presented to the Executive Committee of the DWS and to the Cabinet for approval. These norms and standards will be reflected in a userfriendly booklet that can be used by all.

Once the proposed norms and standards for appropriate levels of water services have been adopted by the DWS, and to enable the sustainable application of the norms and standards, it will be necessary to align policy positions and implementation strategies across stakeholder departments focusing on long term sustainable service delivery; have transparent financing strategies and accountability plans; develop guidelines for good governance and for participatory planning and implementation; provide a list of appropriate technologies for service levels that allow for flexibility; monitor and report on processes and procedures; ensure training and capacity building of officials, local government, implementing agents, and the public; and evaluate the effectiveness of the norms and standards over time.

\section{References}

[1] Department of Water Affairs and Forestry (DWAF), Strategic Framework for Water Services, DWAF: Pretoria, South Africa, pp. 5-12, 2003.

[2] Department of Water Affairs (DWA), National Water Policy Review: Water Policy Positions, DWA: Pretoria, South Africa, pp. 4-14, 2013.

[3] Department of Provincial and Local Government (dplg), Guidelines for the implementation of the National Indigent Policy by municipalities, dplg: Pretoria, South Africa, pp. 4-7, 2005.

[4] Department of Water Affairs (DWA), The Second National Water Resources Strategy (NWRS2), DWA: Pretoria, South Africa, pp. 2-17, 2012. 
[5] National Planning Commission (NPC), National Development Plan: Vision for 2030, NPC: Pretoria, South Africa, pp. 154-161, 2011.

[6] CSIR, Water supply (Chapter 9). Guidelines for Human Settlement Planning and Design, CSIR: Pretoria, South Africa, pp. 9.1-9.38, 2000.

[7] Tapela, B.N., Social Water Scarcity and Water Use, Water Research Commission: Pretoria, South Africa, pp. 73-82, 2012.

[8] Duncker, L.C. \& Wilkinson, M., The application of appropriate sanitation technologies and systems for sustainable sanitation (Chapter 7). The Sustainable Infrastructure Handbook, Vol 1, ed. L van Wyk, Alive2Green: Cape Town, South Africa, pp. 110-121, 2014.

[9] Naidoo, D., Munshi, S. \& Burke, A., Documentation of the WIN-SA Lesson: Moving Up the Water Ladder/Higher Levels of Water Services, Water Research Commission: Pretoria, South Africa, pp. 29-39, 2012.

[10] Burr, P. \& Fonseca, C., Applying a Life-cycle Costs Approach to Water: Costs and Service Levels in Rural and Small Town Areas in Andhra Pradesh (India), Burkina Faso, Ghana and Mozambique, Full Working Paper No 8, IRC International Water and Sanitation Centre: The Hague, pp. 44-67, 2013.

[11] Van der Bliek, J., McCornick, P. \& Clarke, J., (eds). On Target for People and Planet: Setting and Achieving Water-related Sustainable Development Goals, International Water Management Institute (IMWI): Colombo, Sri Lanka, pp. 24-27, 2014.

[12] Department of Water Affairs and Forestry (DWAF), Drinking Water Quality Management Guide for Water Services Authority, SANS 241, DWAF: Pretoria, South Africa, 2005. 